\title{
Long-term cognitive impairments and pathological alterations in a mouse model of repetitive mild traumatic brain injury
}

\section{Jian Luo ${ }^{1,2} *$, Andy Nguyen ${ }^{1,2}$, Saul Villeda ${ }^{1,2 \dagger}$, Hui Zhang 1,2, Zhaoqing Ding ${ }^{1,2}$, Derek Lindsey ${ }^{2}$, Gregor Bieri ${ }^{1,2}$, Joseph M. Castellano ${ }^{1,2}$, Gary S. Beaupre ${ }^{2}$ and Tony Wyss-Coray 1,2*}

1 Department of Neurology and Neurological Sciences, Stanford University School of Medicine, Stanford, CA, USA

${ }^{2}$ Center for Tissue Regeneration, Repair and Restoration, VA Palo Alto Health Care System, Palo Alto, CA, USA

\section{Edited by:}

Denes V. Agoston, Max Planck

Institute, Germany

\section{Reviewed by:}

Sonia Villapol, Uniformed Services

University of the Health Sciences,

USA

Stefan Plantman, Karolinska

Institutet, Sweden

*Correspondence:

Jian Luo and Tony Wyss-Coray,

Department of Neurology and

Neurological Sciences, Stanford

University School of Medicine, VA

Palo Alto Health Care System, 3801

Miranda Avenue, Building 100, Room

D3-111, Mail code: 154W, Palo Alto,

CA 94304, USA

e-mail: jian/@stanford.edu;

twc@stanford.edu

\section{${ }^{+}$Present address:}

Saul Villeda, Department of Anatomy, Eli and Edythe Broad Center of

Regeneration Medicine and Stem Cell Research, University of California, San

Francisco, CA, USA
Mild traumatic brain injury (mTBI, also referred to as concussion) accounts for the majority of all traumatic brain injuries. The consequences of repetitive mTBI have become of particular concern for individuals engaged in certain sports or in military operations. Many mTBI patients suffer long-lasting neurobehavioral impairments. In order to expedite preclinical research and therapy development, there is a need for animal models that reflect the long-term cognitive and pathological features seen in patients. In the present study, we developed and characterized a mouse model of repetitive mTBI, induced onto the closed head over the left frontal hemisphere with an electromagnetic stereotaxic impact device. Using GFAP-luciferase bioluminescence reporter mice that provide a readout of astrocyte activation, we observed an increase in bioluminescence relative to the force delivered by the impactor after single impact and cumulative effects of repetitive mTBI. Using the injury parameters established in the reporter mice, we induced a repetitive $\mathrm{mTBI}$ in wildtype C57BL/6J mice and characterized the long-term outcome. Animals received repetitive mTBI showed a significant impairment in spatial learning and memory when tested at 2 and 6 months after injury. A robust astrogliosis and increased p-Tau immunoreactivity were observed upon post-mortem pathological examinations. These findings are consistent with the deficits and pathology associated with $\mathrm{MTBI}$ in humans and support the use of this model to evaluate potential therapeutic approaches.

Keywords: mild traumatic brain injury, long-term, neurobehavior, bioluminescence, astrogliosis

\section{INTRODUCTION}

Traumatic brain injury (TBI) is a major global health concern, and the CDC has estimated that over 1.5 million people experience a TBI each year in the US. Clinically, mild traumatic brain injury (mTBI, also referred to as concussion) accounts for approximately $80 \%$ of all TBIs, the majority of which result from closed head, concussive impact injuries (1). In military populations, mTBI caused by non-blast concussive impact and/or primary blast events has become the signature injury in the conflicts in Iraq and Afghanistan (2), with an estimated $12-35 \%$ of soldiers experiencing a mTBI during their deployment (3). While most mTBI patients recover without significant long-term consequences, 7$30 \%$ (even up to $60 \%$ in some reports) of individuals are estimated to suffer from a post-concussive syndrome that comprises physical, cognitive, and emotional symptoms $(4,5)$. These long-lasting symptoms include memory impairments, difficulty in concentration, depression, apathy, and anxiety $(4,5)$. Because these symptoms are usually observed in the absence of significant structural damage, patients sustaining mTBI are difficult to diagnose (6), and routine clinical and laboratory evaluations of mTBI patients often fail to show clear morphological brain defects.
Recently, the consequences of repetitive mTBI from multiple concussions have become of particular concern for individuals engaged in certain sports or in military operations because they are at high risk of repeated concussion $(7,8)$. Military personnel often have several mTBI exposures over the course of their lives and possibly within single deployments $(9,10)$. Epidemiological studies revealed that about $60 \%$ of retired professional football players sustained at least one concussion during their careers and approximately 25\% experienced repeated injuries (11). Recurrent brain injuries, even when mild, may interfere with neuropsychological recovery $(9,12)$. Therefore, repetitive mTBI has been associated with greater severity of symptoms, with longer recovery time, and with earlier onset of age-related memory deficits and dementia (13). Repeated concussions have also been associated with chronic traumatic encephalopathy (CTE), a neurodegenerative disorder with progressive impairments of memory and cognition, as well as depression, anxiety, and motor abnormalities (14-16).

Our understanding of the mechanisms of these behavioral deficits is still largely incomplete. Animal models would certainly facilitate a better understanding of the pathological and behavioral outcomes as a result of concussion (17-19). Therefore, there 
has been a recent focus in developing animal models of mTBI. A large number of animal models of mTBI have been developed and they have been effective in characterizing the pathological and behavioral changes after acute (i.e., single impact) mTBI. Current animal models of concussion have included mild to moderate versions of fluid-percussion impact (FPI), controlled cortical impact (CCI), and weight drop injury $(20,21)$. Although these models have demonstrated mild to moderate injury severity levels, most are not capable of mimicking true closed-head concussive injury. Furthermore, most of the current mTBI models have been reported to produce some degree of immediate or short-term behavioral deficits; however, it is not clear whether these deficits are long-lasting since few of the published studies made long-term observations beyond 1 month $(17,18)$. Therefore, our goal of this study was to develop a clinically relevant closed-head injury of repetitive $\mathrm{mTBI}$ that results in long-term behavioral and pathological alterations modeling mild brain injury in humans. To establish injury parameters, we first employed bioluminescence imaging in reporter mice expressing luciferase under the control of a GFAP promoter (GFAP-luc mice) $(22,23)$. Bioluminescence imaging of GFAP-luc mice enables us to test a relatively large number of injury conditions in a medium-throughput manner by following astrogliosis and neural injury in the same mice throughout the course of injury. We then implemented the injury parameters established in the reporter mice and induced a repetitive $\mathrm{mTBI}$ in wild-type C57BL/6J mice. To further validate the long-term cognitive and pathological effects of the injury model, we performed behavioral testing and post-mortem pathological examinations of brain tissue.

\section{MATERIALS AND METHODS \\ ANIMALS}

The experiments were approved by the Institutional Animal Care and Use Committee of VA Palo Alto Health Care System, and were in accordance with the National Institutes of Health Guide for the Care and Use of Laboratory Animals. Two mouse lines were used: bioluminescence reporter mice expressing luciferase under the control of a GFAP promoter (GFAP-luc mice, FVB/N background) (Caliper Life Science, now part of Caliper Life Science, Hopkinton, MA, USA) $(22,23)$ and wild-type C57BL/6J mice (The Jackson's Laboratory, Bar Harbor, ME, USA). Bedding, nesting material, food, and water were provided ad libitum. Ambient temperature was controlled at $20-22^{\circ} \mathrm{C}$ with 12 -h light/12-h dark cycles. Mice were 2-3 months of age at the beginning of experiments. All behavioral testing was performed in isolated behavior rooms.

\section{A MOUSE MODEL OF REPETITIVE CLOSED-HEAD mTBI}

Closed-head injury was induced using a Benchmark Stereotaxic Impactor (MyNeurolab, St. Louis, MO, USA) with modifications. The Benchmark Stereotaxic Impactor is an electromagnetic stereotaxic impact device capable of producing consistent, graded CCI injuries in adult mice with stereotaxic control of impact location and depth at high velocities (24). Recently it was modified to produce repetitive closed-skull TBI in mice (25). We mounted an actuator on a stereotaxic frame (David Kopf Instruments, Tujunga, CA, USA) at a $40^{\circ}$ angle (Figure 1A, left panel). A rubber tip (25) or self-adhesive bumper (3M, St. Paul, MN, USA) was mounted onto a customized impact probe tip ( $9 \mathrm{~mm}$ in diameter). Mice were anesthetized with isoflurane (2.5\% induction, $1.0 \%$ maintenance) and the scalp was shaved. Mice were placed in the stereotaxic frame and secured in prone position in a customized foam mold, with isoflurane delivered by a gas anesthesia mask (Stoelting, Wood Dale, IL, USA) (Figure 1A, left panel). An ear bar (with the nonpointed end touching the skin) (Stoelting, Wood Dale, IL, USA) was used to assist to position the head. The probe tip was fully extended and lowered until the vertex of the bumper touched the scalp (Figure 1A, middle panel). The stereotaxic manipulator was adjusted so that the vertex of the bumper impacted the scalp at a consistent point in relation to the eye and ear of injury side of the head (Figure 1A, right panel). The center of impact corresponds to the following coordinates: from Bregma: AP $1.2 \mathrm{~mm}$ (1.2 mm anterior to the bregma), ML $4.2 \mathrm{~mm}$ (4.2 mm lateral to the midline), according to the mouse brain atlas (26). To induce an impact, the tip was retracted automatically. The ear bar was gently removed to allow the head to move with little or no restraint upon impact. The stereotaxic device was then moved down, and the electromagnetic device was triggered, driving the tip into the head at a speed and a dwell time set from the electronics control box. The size and shape of the probe tip and bumper, the distance that stereotaxic device is moved down (impact depth), the speed the probe tip travels (impact speed), and the dwell time can be varied to achieve concussions of different severities. In addition, the location and the angle at which the probe tip impacted the head (impact location and angle) can be adjusted through the stereotaxic manipulator. After impact, the mice were allowed to recover from anesthesia on a warming pad and then returned to their home cages. For repetitive injuries, identical impact procedures were performed at an interval of $24 \pm 1 \mathrm{~h}$. For sham injuries, the same procedure was performed except that the impact device was discharged in the air; the handling of the mice and duration of anesthesia were identical for both mTBI and sham procedures $(24,25)$.

In this study, we chose to vary impact speeds $(3-5 \mathrm{~m} / \mathrm{s})$ for the injury phase while keeping other parameters (impact depth: $3 \mathrm{~mm}$; dwell time: $0.2 \mathrm{~s}$; impact probe tip: $9 \mathrm{~mm}$; and impact angle: $40^{\circ}$ ) consistent. Similar parameters have been used to induce mTBI in CCI or closed-skull concussions $(24,25)$. A total of 106 mice (included both lines) were used in this study. There were no immediate fatalities with these settings. Subcutaneous hemorrhages were observed in GFAP-luc mice impacted with $5 \mathrm{~m} / \mathrm{s}$ of impact speed (10\%) and with repetitive impacts (25\%). These mice with excluded from behavioral and pathological analyses. Subcutaneous hemorrhages or skull fractures were not observed in C57BL/6J mice after three impacts of repetitive injury at $4 \mathrm{~m} / \mathrm{s}$.

\section{IN VIVO BIOLUMINESCENCE IMAGING}

Bioluminescence emitted from the brain of GFAP-luc mice was detected with the In vivo Imaging System (IVIS Spectrum; Caliper Life Science, Alameda, CA, USA) as previously described (22, 27, 28). Briefly, mice were injected intraperitoneally with $150 \mathrm{mg} / \mathrm{kg}$ D-luciferin $10 \mathrm{~min}$ before imaging and anesthetized with isoflurane during imaging. Photons emitted from living mice were acquired as photons per second per square centimeter per steradian using LIVINGIMAGE software (version 4.0) and integrated 


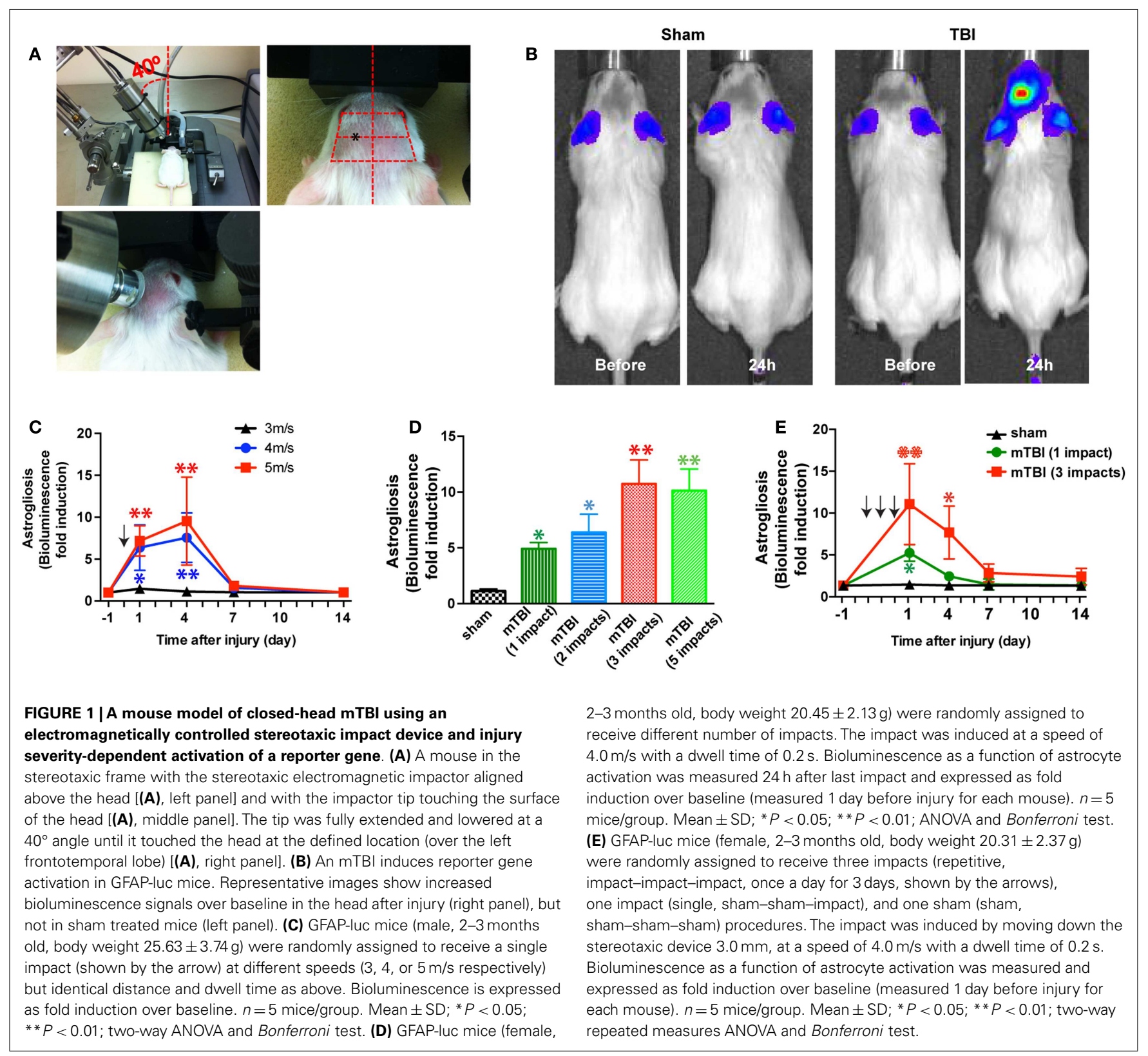

over $3 \mathrm{~min}$. For bioluminescence quantification, a region of interest was manually selected over the head and kept constant for all experiments; the signal intensity was converted into photons per seconds per square millimeter per steradian. For longitudinal comparison of bioluminescence, baseline imaging was performed $24 \mathrm{~h}$ before impact injury and bioluminescence was expressed as fold induction over baseline levels for each mouse.

\section{SMART-HOMECAGE MONITORING}

The Smart-Homecage, developed by AfaSci, Inc. ${ }^{1}$ (Redwood City, CA, USA), is a home cage behavior monitoring system (29). This system is composed of infrared (IR) matrices for activity,

${ }^{1}$ http://www.afasci.com/ position, and locomotion detection. A fresh cage was inserted into the Smart-Homecage platform. The mouse was placed in the cage and allowed to explore the cage for $5 \mathrm{~min}$. Parameters of exploratory behavior, such as travel distance and rearing were calculated automatically by CageScore software.

\section{ROTA-ROD TESTING}

Mice were trained and tested on an accelerating Rota-Rod (Ugo Basile North America Inc., Collegeville, PA, USA) for motor strength and coordination. The test procedure was performed according to the SOP developed by the EUMORPHIA consortium $^{2}$. There is no training period prior to the test phase as this

\footnotetext{
${ }^{2}$ http://empress.har.mrc.ac.uk/viewempress/pdf/ESLIM_010_001.pdf
} 
actually improves the reproducibility and strain ranking effects across centers (30). The Rota-Rod was set to accelerate from 5 to $30 \mathrm{rpm}$ during a test period of $5 \mathrm{~min}$. Mice were tested three times with an inter-trial interval of $20 \mathrm{~min}$, and the latency to fall onto the transducer platform was automatically recorded. The average latency of the three trials was calculated for the analysis.

\section{DIGIGAIT ANALYSIS}

The DigiGait System (Mouse Specifics, Boston, MA, USA) is a non-invasive method for quantitative comparison of gait dynamics. Each mouse was placed on a transparent belt of a treadmill enclosed by a plastic scaffold. The speed of the belt was set at $20 \mathrm{~cm} / \mathrm{s}$ for all mice. The mouse was imaged ventrally by a highspeed camera, which captured the dynamics of the paws and corresponding limbs while walking on the belt. The stride length and other spatial and temporal gait indices for each limb were analyzed automatically with the DigiGait Imaging System.

\section{ELEVATED ZERO MAZE TESTING}

The elevated zero maze was used to test for unconditioned anxietylike behaviors (31). The maze is a circular platform (outer diameter $46 \mathrm{~cm}$, width $5.5 \mathrm{~cm}$ ) that was elevated $40 \mathrm{~cm}$ above the floor. It consists of two walled (white Plexiglas) sectors separated by two open sectors of equal length. Each test session was started by placing the mouse in one of the two open sectors facing a closed sector. The mouse was allowed to freely explore for $5 \mathrm{~min}$. Activity was recorded using a video-camera placed above the maze and TopScan software (Clever Sys., Inc., Reston, VA, USA). Total path traveled in the different sectors, percent of time spent in the open and closed sectors, and number of open sector entries were automatically analyzed by TopScan software. The mouse was then returned to its home cage and the maze was cleaned with a 70\% ethanol between animals.

\section{RADIAL ARM WATER MAZE}

Spatial learning and memory was assessed using the radial arm water maze (RAWM) paradigm following the exact protocol described previously (32). The goal arm location containing a platform remained constant throughout the training and testing phase, while the start arm was changed during each trial. On day 1 during the training phase, mice were trained for 15 trials, with trials alternating between a visible and hidden platform. On days 2 and 3 during the testing phase, mice were tested for 15 trials with a hidden platform. Entry into an incorrect arm was scored as an error, and errors were averaged over training blocks (three consecutive trials).

\section{Y-MAZE}

The Y-maze is made of solid white plastic and consisted of two symmetrical arms and one longer arm at $120^{\circ}$ angles (longer arm, $20.7 \mathrm{~cm}$ length $\times 12.7 \mathrm{~cm}$ height $\times 7.62 \mathrm{~cm}$ width; equal arms, $15.24 \mathrm{~cm}$ length $\times 12.7 \mathrm{~cm}$ height $\times 7.62 \mathrm{~cm}$ width) $(33)$. At the beginning of trials, mice were placed in the end of the longer arm and allowed to freely explore the three arms for $5 \mathrm{~min}$. Arm entry was defined as having all four limbs inside an arm. The maze was cleaned with $70 \%$ ethanol between animals and before the first animal to eliminate traces of odor. The number of arm entries and the number of triads were recorded in order to calculate the alternation percentage, which was calculated by dividing the number of triads by the number of possible alternations multiplied by 100. A triad was defined as a set of consecutive arm entries (34).

\section{CONTEXTUAL FEAR CONDITIONING}

Contextual fear conditioning was performed following the previously published procedures (32) with minor modifications. In this task, mice learned to associate the environmental context (fear conditioning chamber) with an aversive stimulus (mild foot shock; unconditioned stimulus, US) enabling testing for hippocampaldependent contextual fear conditioning. As contextual fear conditioning is hippocampus and amygdala-dependent, the mild foot shock was paired with a light and tone cue (conditioned stimulus, CS) in order to also assess amygdala-dependent cued fear conditioning. Conditioned fear was displayed as freezing behavior. Specific training parameters are as follows: tone duration is $30 \mathrm{~s}$; sound level is $70 \mathrm{~dB}, 2 \mathrm{kHz}$; shock duration is $2 \mathrm{~s}$; and intensity is $0.6 \mathrm{~mA}$. More specifically, on the first day of testing (training), each mouse was placed in a fear conditioning chamber and allowed to explore for $2 \mathrm{~min}$ before delivery of a 30 -s tone $(70 \mathrm{~dB})$ ending with a 2 -s foot shock $(0.6 \mathrm{~mA})$. Two minutes later, a second CS-US pair was delivered. Shocks were delivered through the grid floor and were controlled by FreezeScan software (Clever Sys., Inc., Reston, VA, USA). On the second day, each mouse was placed in the same fear conditioning chamber containing the same context as the training day, but without administration of a CS or foot shock. Freezing was analyzed for 1-3 min. To analyze cued freezing behavior, the mice were placed in a new context $1 \mathrm{~h}$ later that contained a different odor (3\% acetic acid), cleaning solution, floor texture, chamber walls, and shape. Animals were allowed to explore for $2 \mathrm{~min}$ before being re-exposed to the CS. Freezing was analyzed for 1-3 min. Freezing was measured using a FreezeScan video tracking system and software (Clever Sys., Inc., Reston, VA, USA).

\section{TISSUE PROCESSING}

Mice were anesthetized with $400 \mathrm{mg} / \mathrm{kg}$ chloral hydrate (SigmaAldrich) and transcardially perfused with $0.9 \%$ saline $(22,28)$. Brains were removed and postfixed in phosphate-buffered $4 \%$ paraformaldehyde, $\mathrm{pH} 7.4$, at $4^{\circ} \mathrm{C}$ for $48 \mathrm{~h}$ and sectioned at $40 \mu \mathrm{m}$ with a sliding microtome 2010 (Leica, Allendale, NJ, USA). The sections were collected serially in 12 tubes and stored in cryoprotective medium $(22,28)$.

\section{CRESYL VIOLET STAINING}

Brain sections (every 12th section) were mounted on Superfrost plus slides (Fisher Scientific, Pittsburgh, PA, USA), air-dried, rehydrated, stained with $0.02 \%$ Cresyl Violet (Sigma) in acetate buffer ( $\mathrm{pH} 3.2)$, then dehydrated through a series of alcohols, cleared in xylene, and coverslipped (28). Neuronal damage/loss was assessed based on the appearance of gaps or thinning and disappearance of the Nissl substance in the CA1 and CA3 pyramidal cell layers. The lesion area was quantified with MetaMorph Imaging software (Molecular Devices, Downingtown, PA, USA).

\section{IMMUNOHISTOCHEMISTRY, LIGHT MICROSCOPY, AND IMAGE ANALYSIS}

Immunohistochemistry was performed on free-floating sections (every 12th section) following standard procedures $(22,28)$. 
Primary antibodies were against: cleaved caspase-3 (1:1000, Cell Signaling Technology, Danvers, MA, USA), GFAP (1:1000, Dako, Carpinteria, CA, USA) (35), p-Tau (Ser202/Thr205, AT8) (1:1000, Pierce, Rockford, IL, USA) (36), and p-CREB (Ser 133) (1:1000, Millipore, Billerica, MA, USA) (37). After overnight incubation, primary antibody staining was revealed using biotinylated secondary antibodies and the ABC kit (Vector, Burlingame, CA, USA) with Diaminobenzidine (DAB, Sigma-Aldrich). Photographs were acquired using a BX51 microscope (Olympus) and a SPOT Flex shifting pixel CCD camera with SPOT Advanced software (SPOT Imaging Solutions, Sterling Heights, MI, USA) under identical conditions and settings. The immunoreactivity was quantified as the percent area covered by ImageJ software (NIH, Bethesda, MD, USA). Our initial observations revealed pathological changes mainly from 0.98 to $-2.06 \mathrm{~mm}$ to Bregma, and we therefore restricted our quantification to sections covering that region. This resulted typically in six and seven sections separated roughly by $12 \mu \mathrm{m} \times 40 \mu \mathrm{m}$, with half of the sections containing hippocampus. We therefore performed image analysis in five sections/animal for cortex and corpus callosum, and three sections/mouse for hippocampus. The images were first converted to eight-bit gray-scale images and then converted into binary positive/negative images by thresholding held constant for all images in a given brain region. Percent area fraction covered by the threshold was determined by ImageJ. The average of values obtained from the three or five sections was used for each animal for statistical analysis.

\section{DATA ANALYSIS}

Data are presented as mean $\pm \mathrm{SD}$ or mean \pm SEM depending on the type of experiment. Statistical analysis of behavioral measurements was performed with GraphPad Prism software (version 6) using ANOVA (regular or repeated measures) and Bonferroni post hoc test or two-tailed Student's $t$-test where appropriate. $P<0.05$ was considered statistically significant.

\section{RESULTS}

In this study, we carried out two series of experiments: the first to investigate injury (impact intensity)-dependent responses in the GFAP-luc reporter mice (FVB/N genetic background) to establish injury parameters, and the second to investigate the behavioral and pathological outcome of repetitive closed-head concussive brain injury based on the above parameters in wild-type C57BL/6J mice.

\section{A MOUSE MODEL OF REPETITIVE CLOSED-HEAD mTBI}

In the first series of experiments we employed bioluminescence imaging, which enables us to follow astrogliosis and neural injury in the reporter mice expressing luciferase under the control of a GFAP promoter (GFAP-luc mice) (on FVB/N genetic background) $(22,23)$. Neuronal injury is closely tied to astrogliosis, and we and others have previously shown that bioluminescence intensity in the GFAP-luc mice correlates significantly with astrogliosis assessed by immunohistochemistry and with neural injury in brain injury models of excitotoxicity and experimental autoimmune encephalomyelitis $(22,23)$. In this study, we utilized this technique to take advantage of testing a relatively large number of injury conditions in a medium-throughput manner while studying the same mouse throughout the course of injury. In an initial experiment, a mild traumatic impact (impact speed: $4 \mathrm{~m} / \mathrm{s}$ ) to the head led to a reproducible, significant increase in bioluminescence in the brain (Figure 1B). Notably, no significant increase in bioluminescence was observed after a sham procedure, suggesting that the sham procedure caused negligible disturbance to the brain. To determine whether different degrees of injury cause different induction of bioluminescence signal, we impacted mice at different impact speeds ( 3,4 , and $5 \mathrm{~m} / \mathrm{s}$, respectively) and observed a dosedependent increase of the bioluminescence signal (Figure 1C). To determine whether repetitive injury is cumulative, we compared the bioluminescence signals in mice receiving different numbers of impacts (impact speed: $4 \mathrm{~m} / \mathrm{s}$; interval: approximately $24 \mathrm{~h}$ ) (Figure 1D). Twenty-four hours after the last impact, there was a significant increase in bioluminescence signal in all injury groups compared with the sham group. There appeared to be a dosedependent increase in bioluminescence signals in mice receiving one to three impacts, but mice receiving five impacts did not show further increase in bioluminescence signals compared with those receiving three impacts (Figure 1D). We then compared the time course of bioluminescence signals in mice receiving a single impact with those receiving three impacts (Figure 1E). In the single-impact group, bioluminescence signals increased significantly at $24 \mathrm{~h}$ after impact $(P<0.05$, compared with baseline), but deceased significantly at day $3(P>0.05$, compared with baseline), and returned to pre-injury levels at day 7 . The repetitive group showed significantly higher bioluminescence signals at $24 \mathrm{~h}$ after the third impact than the single-impact group $(P<0.01$, compared with baseline and with the single-impact group). While the bioluminescence signals in the repeat-impact group decreased to the same degree as in the single group at day 3 , they were significantly higher overall $(P<0.01$, compared with baseline and with the single-impact group). At days 7 and 14, the bioluminescence signals in the repeat-impact group were higher than baseline and the single-impact group, but did not reach statistical significance $(P>0.05)$.

To determine whether mTBI in our model causes motor deficits, we performed Rota-Rod test. There was no significant difference between injured (one or three impacts) and sham groups (Figure 2A). To determine whether mTBI causes long-term cognitive deficits, we performed a fear conditioning test 3 months after injury (Figure 2B). During fear conditioning training, mTBI mice receiving three impacts exhibited reduced baseline freezing time (Figure 2C). Importantly, mTBI mice receiving three impacts demonstrated decreased freezing time during both cued and contextual memory testing compared with sham animals $(P<0.05)$. In contrast, mTBI mice receiving one impact did not differ significantly from sham mice in freezing behavior at baseline, nor did they differ significantly in cued or contextual memory (Figure 2C). Thus, repetitive mTBI in our close-head model produces consistent mild injuries, leading to long-term memory, and cognitive deficits. In addition, correlation analysis shows that bioluminescence signal in the GFAP-luc mice negatively correlates with freezing behavior in the fear conditioning test $(R=-0.704, P=0.012)$ and with post-mortem $\mathrm{p}$-CREB immunoreactivity $(R=-0.744, P=0.007)$, suggesting that bioluminescence signal can be used as a surrogate marker in our mTBI paradigm. 

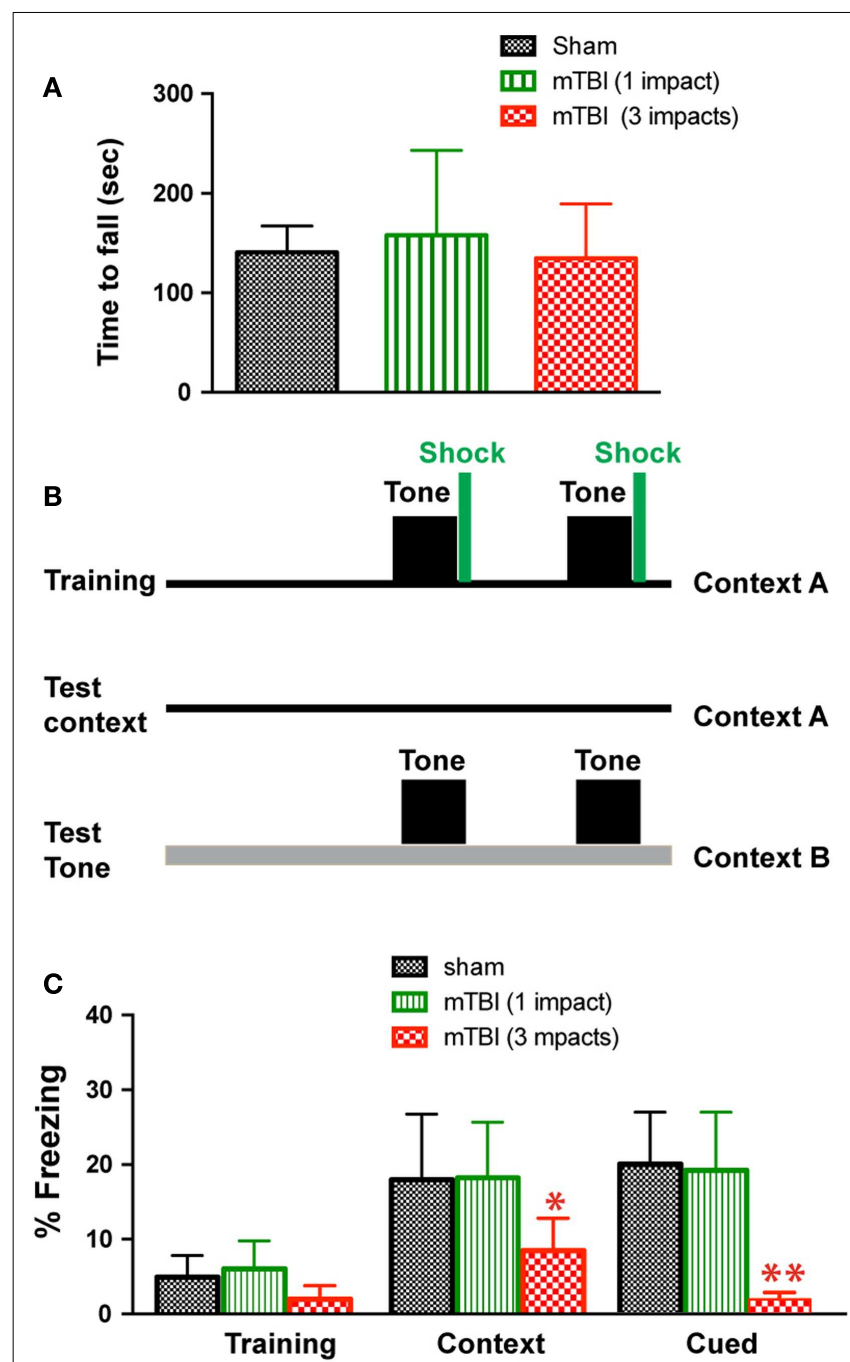

FIGURE 2 | Repetitive $\mathrm{mTBI}$ causes significant cognitive impairments 3 months after injury. Three months after injury, the GFAP-luc mice shown in Figure 1E were tested for motor function using a Rota-Rod apparatus (A) and for learning and memory using fear conditioning (B,C). (A) In the Rota-Rod test, latency to fall onto the transducer platform was automatically recorded. The average latency over the three trials was calculated for each mouse. No difference between the mTBI and sham groups were observed (mean $\pm \mathrm{SD}, P>0.05$ by $t$ test). (B) The test paradigm for fear conditioning. (C) The freezing behavior was recorded and analyzed. Mice exposed to $\mathrm{mTBI}$ (three impacts) showed reduced baseline freezing behavior, and context- and cue-related freezing behavior. $n=5$ mice/group. Mean $\pm S D$; ${ }^{*} P<0.05,{ }^{*} P<0.01$; ANOVA and Bonferroni test.

\section{REPETITIVE CLOSED-HEAD mTBI CAUSED COGNITIVE DEFICITS 6 MONTHS AFTER INJURY IN WILD-TYPE C57BL/6J MICE}

Based on the results of astrogliosis and the behavioral deficits observed in the reporter mice, the following injury parameters were selected: impact speed: $4 \mathrm{~m} / \mathrm{s}$; number of impacts: 3 ; and injury interval: $24 \mathrm{~h}$. We induced repetitive mild brain injury and characterized the outcome in wild-type C57BL/6J mice, a mouse line more suitable for behavioral characterization and more commonly used in the field. We employed a battery of behavioral tests (Figure 3A) and performed post-mortem histopathological analysis to investigate whether the repetitive mTBI in our model is capable of producing impairments similar to what is observed in human mTBI patients.

\section{INCREASED EXPLORATORY BEHAVIOR BASED ON HOMECAGE MONITORING}

At weeks 1 and 2, mTBI mice showed significantly increased exploratory behavior during the first $5 \mathrm{~min}$ in a new environment, shown by increased travel distance and rearing behavior (Figures 3C,D). However, no significant difference was found at 6 weeks after injury, suggesting that this effect recovered. In addition, there was no difference in either travel distance or rearing behavior over 60-min monitoring (not shown), suggesting mTBI did not cause significant motor deficits.

\section{NO SIGNIFICANT MOTOR DEFICITS AFTER REPETITIVE mTBI}

Absence of significant motor deficits in these mice was further confirmed using Rota-Rod (Figure 3B), and the DigiGait analysis system (Mouse Specifics, Inc.), which offers an automated analysis of a large number of gait parameters. There was no consistent difference between sham and mTBI mice in any of the parameters measured, including stride length, stride width, stride frequency, and stride length variability (Table $\mathbf{1}$ ).

\section{NO ANXIETY-LIKE BEHAVIOR IN THE ELEVATED ZERO MAZE TESTS}

To investigate whether mTBI mice show anxiety-like behavior we employed an elevated zero maze test (31) and observed no differences between mTBI and sham groups. Specifically, the mTBI mice spent similar amounts of time in the closed arms of the maze (Figure 4A). In addition, the number of bouts and the distance moved in the entire maze were not significantly different between the two groups (Figures 4B,C). Thus, mTBI mice did not display unconditioned anxiety-like behaviors.

\section{IMPAIRED SPATIAL LEARNING AND MEMORY 2 MONTHS AFTER REPETITIVE mTBI}

To determine whether the repetitive mTBI in our model led to cognitive impairments in mice we assessed hippocampal-dependent learning and memory using the RAWM paradigm ( 2 months after injury). All mice showed similar spatial learning capacity during the training phase regardless of treatment. However, by the end of the testing phase animals exposed to repetitive mTBI exhibited impaired learning and memory deficits, committing significantly more errors in locating the target platform than sham animals (Figure 5).

\section{CUED AND CONTEXTUAL MEMORY DEFICITS 6 MONTHS AFTER REPETITIVE $\mathrm{mTBI}$}

To determine whether the repetitive mTBI in our model led to cognitive impairments at a later time point, we performed Y-maze and contextual fear conditioning tests at 6 months after injury. There was no difference in spontaneous alternation in the Y-maze test (Figure 6A). In the fear conditioning test, both the sham and mTBI animals exhibited similar baseline freezing behavior during training (Figure 6B). However, the mTBI group performed significantly worse in the contextual test than the sham group (Figure 6B), as 


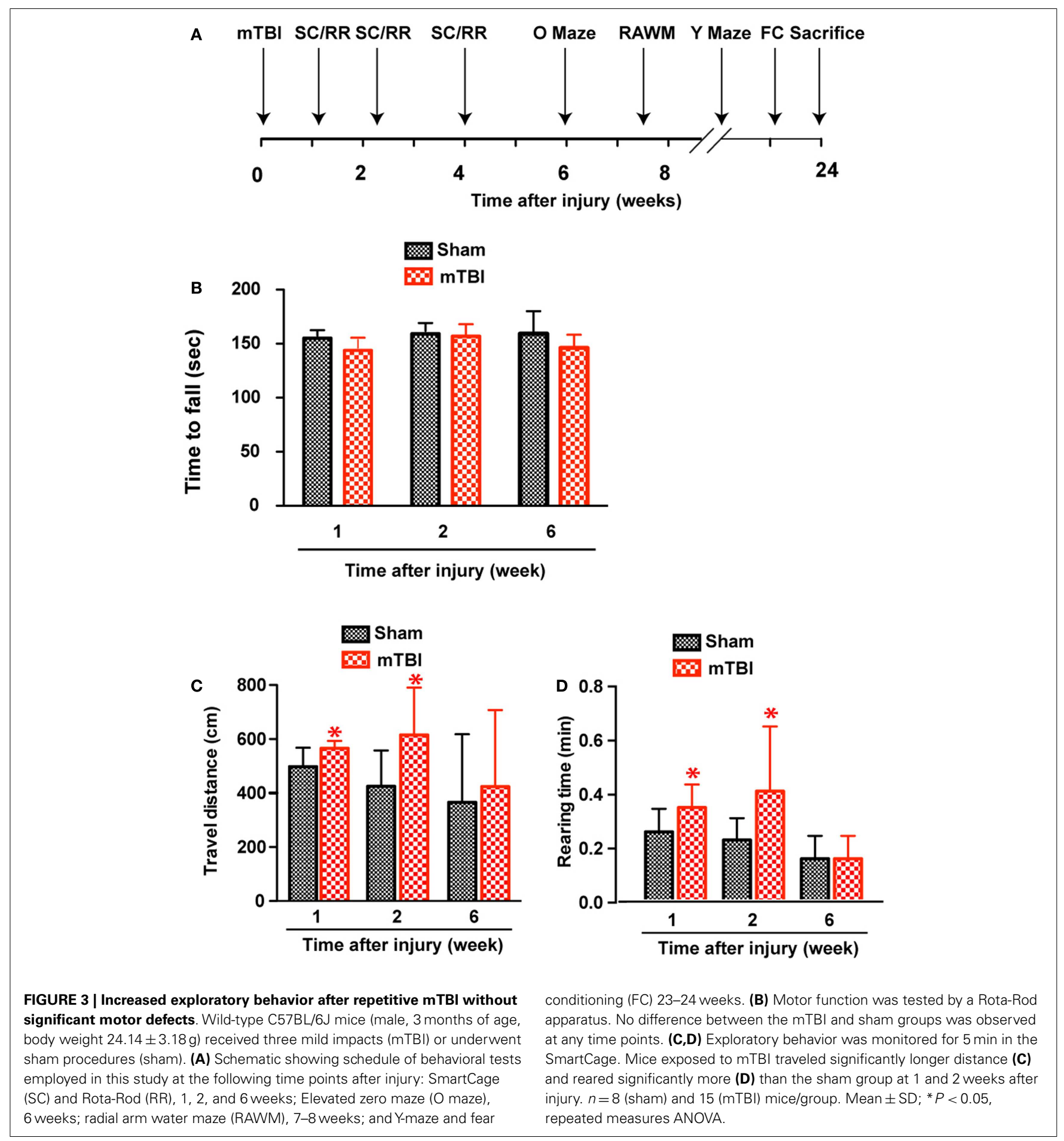

shown by the significantly decreased freezing behavior. In addition, the mTBI group showed decreased freezing behavior in cued memory retrieval detected $24 \mathrm{~h}$ after training when re-exposed to the CS (tone and light) in a novel context (Figure 6B). Results from contextual and cued periods were consistent with our observations in FVB/N mice (Figure 2). Together, these data demonstrate that repetitive $\mathrm{mTBI}$ impairs learning and memory as long as 6 months after injury in our model.

\section{PROMINENT PATHOLOGICAL ALTERATIONS AFTER REPETITIVE mTBI}

To determine if the observed behavioral deficits are associated with pathological changes ( 6 months after injury), we performed post-mortem pathological examinations. We first performed cresyl violet staining and did not observe contusions or obvious cell loss (for example, percent area covered was 76.97 \pm 4.53 in CA3 in $\mathrm{mTBI}$ and $79.29 \pm 5.46$ in sham, mean \pm SEM, $P=0.757$ by $t$ test). We then performed immunohistochemistry using antibodies 
Table 1 | Gait parameters 2 weeks after injury.

\begin{tabular}{|c|c|c|c|c|c|c|c|c|}
\hline & \multicolumn{2}{|c|}{ Left front } & \multicolumn{2}{|c|}{ Left hind } & \multicolumn{2}{|c|}{ Right front } & \multicolumn{2}{|c|}{ Right hind } \\
\hline & Sham & mTBI & Sham & mTBI & Sham & mTBI & Sham & mTBI \\
\hline \% Swing/stride & $38.16 \pm 1.07$ & $39.51 \pm 0.98$ & $35.59 \pm 0.93$ & $35.23 \pm 1.44$ & $39.74 \pm 0.09$ & $38.81 \pm 0.72$ & $35.29 \pm 1.05$ & $35.67 \pm 0.86$ \\
\hline Braking (s) & $0.087 \pm 0.002$ & $0.096 \pm 0.005$ & $0.038 \pm 0.004$ & $0.041 \pm 0.003$ & $0.088 \pm 0.004$ & $0.086 \pm 0.005$ & $0.043 \pm 0.002$ & $0.046 \pm 0.002$ \\
\hline$\%$ Braking/stride & $30.47 \pm 0.57$ & $31.20 \pm 1.68$ & $13.65 \pm 1.37$ & $13.33 \pm 1.02$ & $30.76 \pm 1.60$ & $28.83 \pm 1.96$ & $15.96 \pm 1.14$ & $15.61 \pm 0.83$ \\
\hline$\%$ Propulsion/stride & $31.37 \pm 1.99$ & $29.26 \pm 1.83$ & $50.76 \pm 2.16$ & $52.426 \pm 1.28$ & $29.53 \pm 0.87$ & $32.37 \pm 1.86$ & $48.76 \pm 1.53$ & $48.72 \pm 0.87$ \\
\hline Stance (s) & $0.180 \pm 0.009$ & $0.186 \pm 0.003$ & $0.181 \pm 0.007$ & $0.198 \pm 0.007$ & $0.173 \pm 0.006$ & $0.185 \pm 0.003$ & $0.178 \pm 0.007$ & $0.192 \pm 0.005$ \\
\hline$\%$ Stance/stride & $61.4 \pm 1.073$ & $60.49 \pm 0.083$ & $64.41 \pm 0.093$ & $64.77 \pm 1.44$ & $60.26 \pm 0.090$ & $61.19 \pm 0.72$ & $64.71 \pm 1.05$ & $64.33 \pm 0.86$ \\
\hline Stride length (cm) & $5.80 \pm 0.23$ & $6.17 \pm 0.11$ & $5.63 \pm 0.16$ & $6.11 \pm 0.15$ & $5.74 \pm 0.25$ & $6.03 \pm 0.08$ & $5.53 \pm 0.21$ & $5.95 \pm 0.15$ \\
\hline Stride (s) & $0.290 \pm 0.011$ & $0.309 \pm 0.005$ & $0.281 \pm 0.008$ & $0.305 \pm 0.007$ & $0.288 \pm 0.012$ & $0.302 \pm 0.004$ & $0.276 \pm 0.010$ & $0.298 \pm 0.007$ \\
\hline Stance width $(\mathrm{cm})$ & $1.70 \pm 0.06$ & $1.67 \pm 0.04$ & $2.56 \pm 0.07$ & $2.49 \pm 0.04$ & NA & NA & NA & NA \\
\hline
\end{tabular}
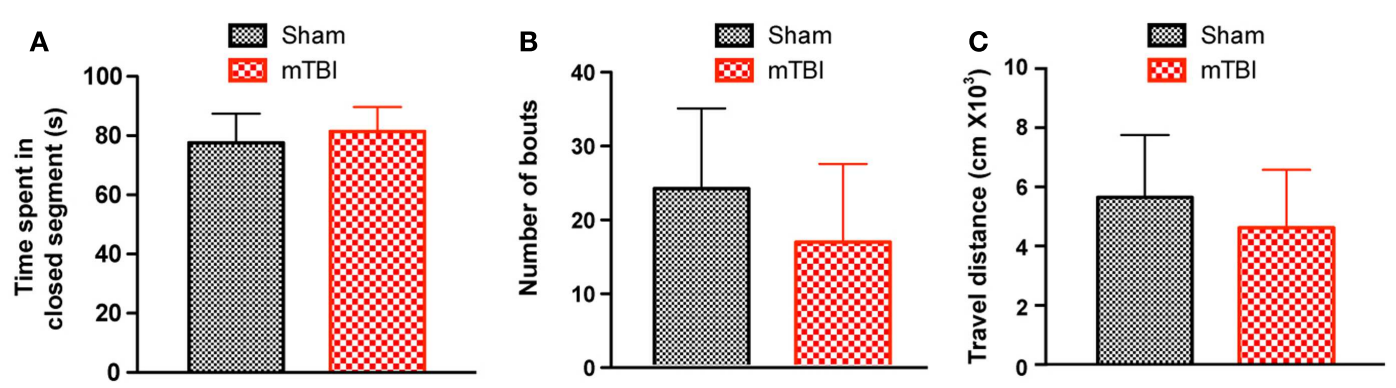

FIGURE 4 | No significant difference was observed in the zero maze test 6 weeks after repetitive brain injury. Wild-type C57BL/6J mice (male, 3 months of age) received three mild impacts (mTBI) or underwent sham procedures (sham), and were assessed for anxiety using the elevated zero maze. The results were expressed as time spent in the closed segment (A), number of bouts (B), and travel distance (C). $n=8$ (sham) and 15 (mTBI) mice/group. Mean \pm SD. against cleaved caspase- 3 (marker of apoptotic cell death, but we observed only a few caspase- 3 positive cells/section after mTBI, which was not significantly different from that of sham), GFAP (a marker of astrogliosis), p-Tau (a marker of impaired axonal transport and axonal damage), and p-CREB [a marker of activation of cAMP responsive element binding protein (CREB) pathway related to memory formation and retention].

\section{STRONG ASTROGLIOSIS AFTER REPETITIVE mTBI}

In mice exposed to the repeat-impact $\mathrm{mTBI}$, there was prominent astrogliosis throughout the brain. Astrocytes showed morphological characteristics of activation, including hypertrophic appearances with thick, densely labeled processes, and large cell bodies (Figure 7). Semi-quantitative estimation revealed that the GFAP immunoreactivity was significantly increased in the ipsilateral cortex (under the impact), hippocampus (CA3 region), and corpus callosum in the mTBI group compared with the sham group (Figure 7).

\section{AXONAL DEGENERATION AFTER REPETITIVE mTBI}

In sham treated mice, weak $\mathrm{p}$-Tau immunoreactivity was observed in a few, scattered cells in the brain; in contrast, stronger
p-Tau immunoreactivity was observed consistently from 0.74 to $-1.82 \mathrm{~mm}$ to Bregma (26) (Figure $\mathbf{8 A}$ ), in regions including the ipsilateral corpus callosum, cortex, hippocampus, septal nucleus, and amygdala (Figure $\mathbf{8 B}$ ). In addition, weaker p-Tau immunoreactivity was also observed in the contralateral side (Figure 8A).

\section{REDUCED p-CREB IMMUNOREACTIVITY AFTER REPETITIVE mTBI}

To identify the potential molecular mechanisms responsible for the observed cognitive deficits, we examined the activation of CREB signaling. The CREB signaling pathway plays a critical role in neuronal survival and in memory formation and cognitive function $(38,39)$. Previous studies have shown this pathway is altered in moderate to severe TBI $(40,41)$, but its role in mTBI has not been investigated. We therefore performed immunohistochemistry and compared p-CREB immunoreactivity in both mTBI and sham brains. There was a significant reduction of $\mathrm{p}$-CREB immunoreactivity in the hippocampus (CA3 neurons) and amygdala (the central nucleus, CeA) of the mice receiving mTBI compared with sham animals (Figure 9), suggesting the CREB signaling pathway is compromised after mTBI. 


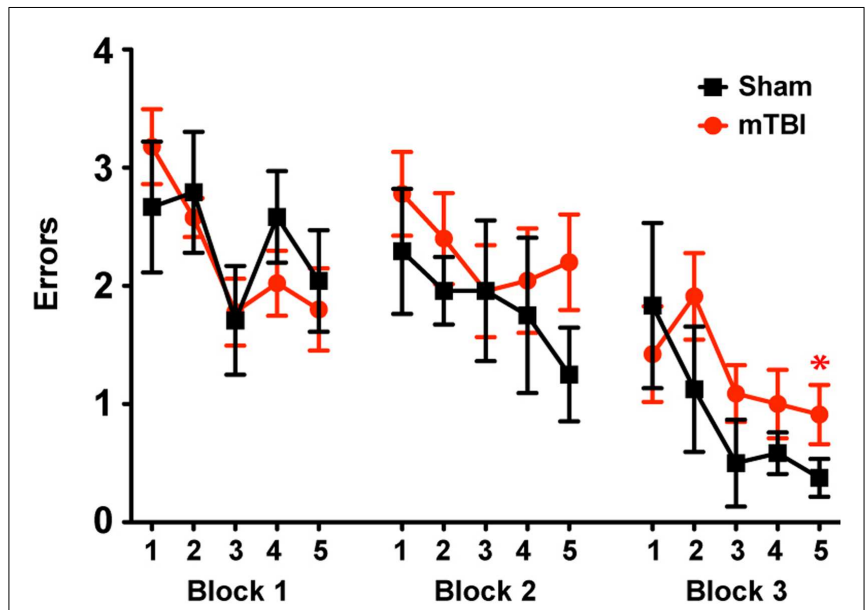

FIGURE 5 | Repetitive $\mathrm{mTBI}$ causes significant cognitive impairments 2 months after injury. Wild-type C57BL/6J mice (male, 3 months of age) received three mild impacts (mTBI) or underwent sham procedures (sham). Spatial learning and memory was assessed using the radial arm water maze (RAWM) paradigm 2 months after injury. On day 1 during the training phase, mice are trained for 15 trials, with trials alternating between visible and hidden platforms. On day 2 during the testing phase, mice are tested for 15 trials with a hidden platform. Entry into an incorrect arm is scored as an error, and the errors are averaged over training blocks (three consecutive trials). Learning and memory deficits were quantified as the number of entry arm errors made prior to finding the target platform. $n=8$ (sham) and 15 (mTBI) mice/group. Mean $\pm \mathrm{SEM}^{*}{ }^{*} P<0.05$, repeated measures ANOVA.

\section{DISCUSSION}

In this study, we have developed and characterized a mouse model of repetitive mTBI using an electromagnetic stereotaxic impact device. We show that animals subjected to three repetitive mTBI with an inter-impact interval of $24 \mathrm{~h}$ displayed long-term (6 months after injury) cognitive impairment, accompanied by prominent pathological changes. These results demonstrate that repetitive $\mathrm{mTBI}$ in mice leads to long-term consequences that resemble those reported in people with repeat exposure to mTBI and CTE.

A major challenge for developing experimental models of mTBI is to replicate the long-term cognitive dysfunction, an important feature of human mTBI patients (20). Although most published mTBI models have demonstrated the ability to produce immediate or short-term behavioral deficits, how long the cognitive dysfunction lasts is unknown, since few studies made longterm observations (beyond 1 month) $(17,18)$. In this study, we employed two frequently used cognitive tests and demonstrated that animals subjected to repetitive mTBI displayed cognitive deficits at 2 (RAWM) and 6 months after injury (contextual fear conditioning).

Cognitive deficits are a common problem seen in patients with repetitive mTBI (21). The hippocampus is an important brain region involved in learning and memory and is susceptible to mild head injury (21). In our model, the repetitively injured mice displayed behavioral deficits in hippocampus-dependent learning paradigms such as RAWM and contextual and cued fear conditioning (33), suggesting that hippocampal function is compromised in the mice in our model. The impacts in our model were applied to the temporal side of the mouse head and thus probably caused damage in the hippocampus and the cortex. The behavioral deficits were observed only in repetitively injured mice that received three impacts but not in the mice that received only a single impact, suggesting that long-term behavior deficits are attributed to the accumulative effects of multiple impacts.

Interestingly, mice exposed to repeated head impacts in our model showed a transient increase in locomotor activity (Figure 3). This is in agreement with observations from athletes who have experienced repeated mild concussive injuries, and often develop secondary problems with attention. These attention deficits are associated with hyperactivity (42). Hyperactivity has been observed after repetitive $\mathrm{mTBI}$ in mice in a weight drop model (43), suggesting that the increased locomotor activity is a common feature after mTBI and provides additional validation of our model.

Pathologically, we observed several changes following repetitive mTBI injury in our model: (1) the absence of gross morphological damage to the brain or obvious loss of neural tissue beneath the point of impacts. (2) Mice subjected to repetitive mTBI show prominent astrogliosis, as shown by increased GFAP immunostaining. (3) Perhaps of greatest interest is the increased immunoreactivity of p-Tau 6 months after the last injury. Tau is an intracellular, microtubule-associated protein that is highly enriched in axons. Hyperphosphorylation and pathological aggregation of Tau is indicative of axonal injury and a common feature of many neurodegenerative diseases with axonal degeneration. Therefore these observations provide strong evidence of traumatic axonal injury in our model, supporting the hypothesis that traumatic axonal injury is the primary pathology associated with adverse outcomes following mTBI (44). Furthermore, we consistently observed pathological changes in the hippocampus. This is not only in agreement with the results of behavioral tests, but also supports the notion that the hippocampus is especially vulnerable to mTBI. In addition, increased p-Tau immunoreactivity and astrogliosis could be pathological signs of CTE (45).

Mice receiving repetitive $\mathrm{mTBI}$ displayed reduced phosphorylation of CREB in the hippocampus. Since the CREB signaling pathway has been implicated in promoting the neuronal survival and in memory formation and cognitive function $(38,39)$, the reduction of CREB signaling may explain at least part of the robust cognitive deficits observed in behavioral tests in our model. Interestingly, the activation of the CREB pathway follows a bi-phasic pattern after TBI. In a fluid-percussion model producing a moderate TBI, CREB was activated at $30 \mathrm{~min}$, peaked at $24 \mathrm{~h}$, and returned to control level at $72 \mathrm{~h}$ after injury in the hippocampus (41). CREB signaling remained unchanged at 2 or 8 weeks postinjury, but was significantly decreased at 12 weeks after injury (40). How mTBI leads to reduced CREB signaling needs further investigation. Secondary injury mechanisms such as oxidative stress and excitotoxicity are both known to inhibit CREB phosphorylation and thus may play a role. It is also noteworthy that reduced immunoreactivity of $\mathrm{p}$-CREB was observed in the absence of significant gross structural damage or neuronal cell loss, suggesting that compromised neuronal integrity may underlie long-term behavioral deficits. 

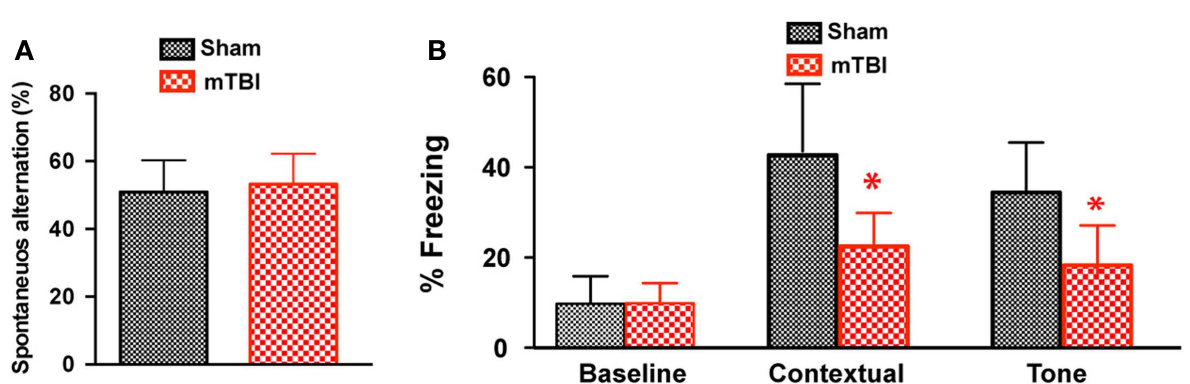

FIGURE 6 | Repetitive mTBI causes significant cognitive impairments 6 months after injury. Wild-type C57BL/6J mice (male, 3 months of age) received three mild impacts (mTBI) or underwent sham procedures (sham). Cognitive function was assessed using the Y-maze (A) and contextual fear conditioning (B) 6 months after injury. (A) In the Y-maze test for working memory, there was no difference in spontaneous alternations between mTBI and sham mice. (B) In the fear conditioning test, no significant statistical difference was apparent in baseline freezing, however, mTBI mice showed significantly impaired context and cued memory compared with sham animals. $n=8$ (sham) and 15 (mTBI) mice/group. Mean \pm SD. ${ }^{*} P<0.05$; by $t$ test.

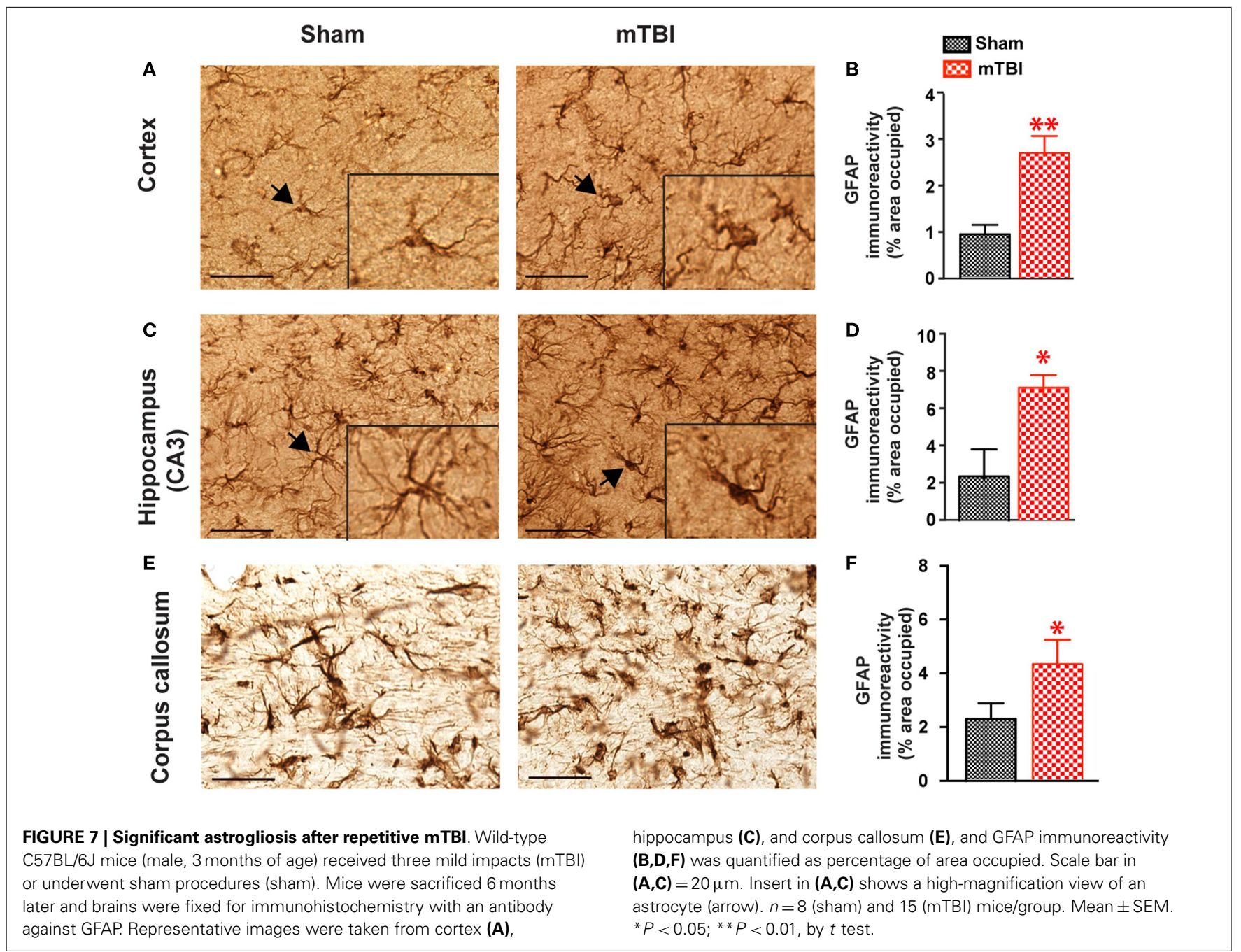

GFAP is an extensively studied TBI biomarker and serum GFAP concentration is found to be predictive of death or poor outcome (46). Therefore, in this study we utilized a bioluminescence in vivo imaging technique in GFAP reporter mice. We have previously shown that the bioluminescence signal in the GFAP-luc mice correlates significantly with astrogliosis assessed by immunohistochemistry and bioluminescence imaging of these reporter mice is more sensitive in detecting 


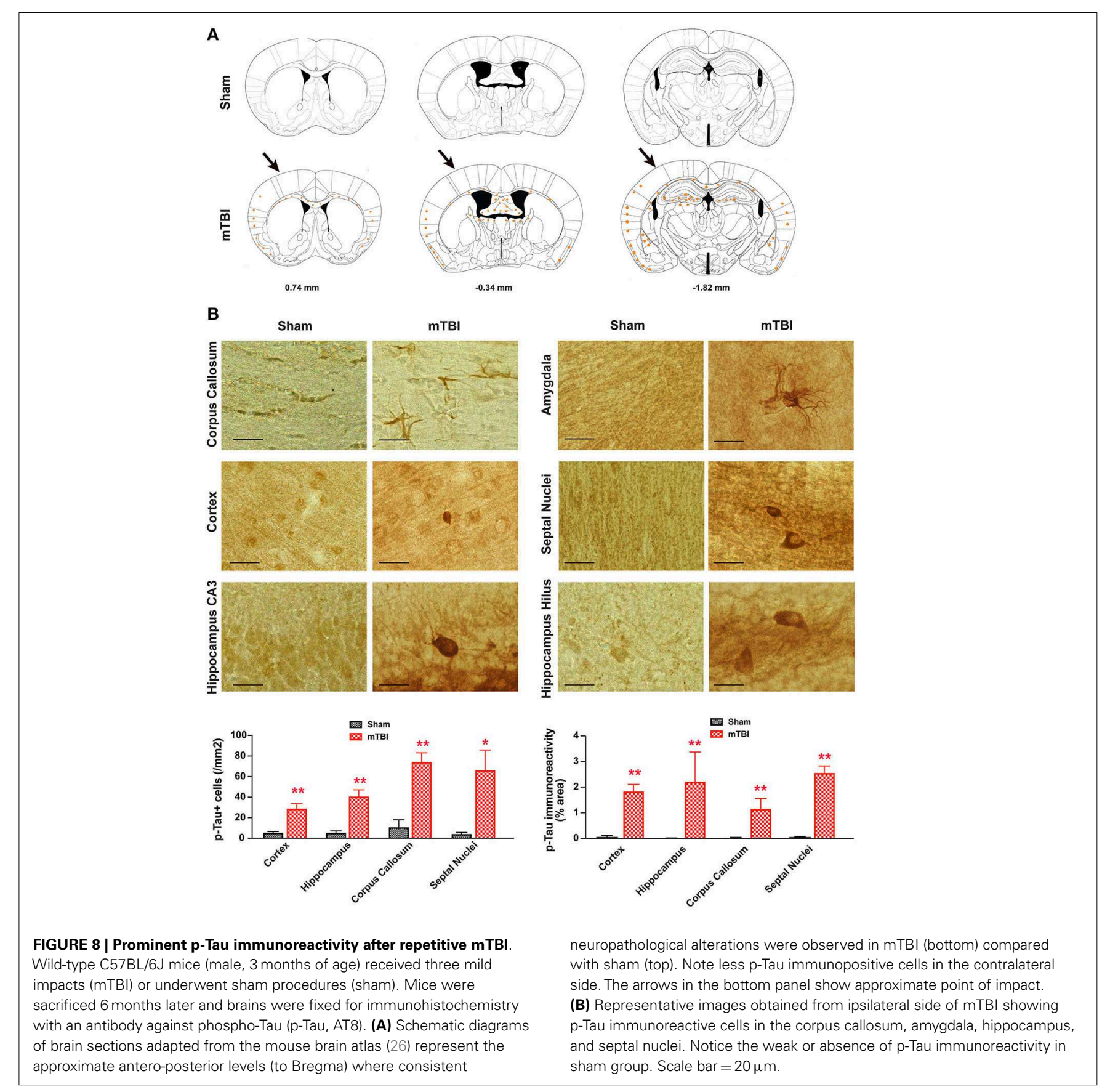

astrogliosis than immunohistochemistry in a model of autoimmune encephalomyelitis $(22,23)$. We show here that the GFAP-luc reporter gene is also responsive to $\mathrm{mTBI}$ and can be used to monitor the initial astroglial response to mild brain injury and maybe more importantly, could be used to monitor the efficacy of experimental treatments for mTBI.

In our model the impact is delivered non-invasively and directly to the mouse head, without surgical intrusions. Our choice of the impact force $(4 \mathrm{~m} / \mathrm{s})$ produces no skull fracture, nor external damage to the brain tissue. In addition, the impacts do not induce significant motor deficits or anxiety, indicating the injury did not affect the animals' well being and thus allows a reliable assessment of the cognitive consequences of repetitive impacts to the brain (47). Our setup allows for accurate delivery of repetitive mild injuries to the same subject. The procedure is simple and rapid and can be performed without craniotomy or other manipulations to the head or skull. Thus our model is suitable for medium- to highthroughput screening of therapeutic compounds in a closed head, mild brain trauma.

In conclusion, we have developed a mouse model of repetitive mTBI with long-term behavioral and pathological sequelae, which resemble those observed in human mTBI patients. The model 


\section{A}
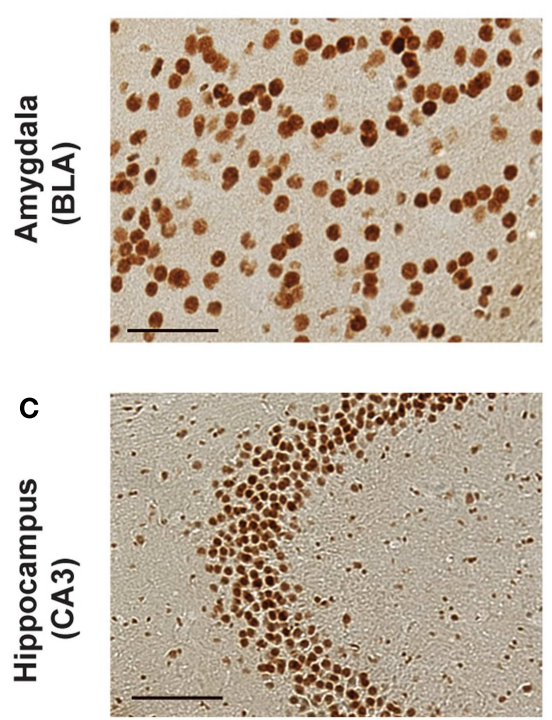

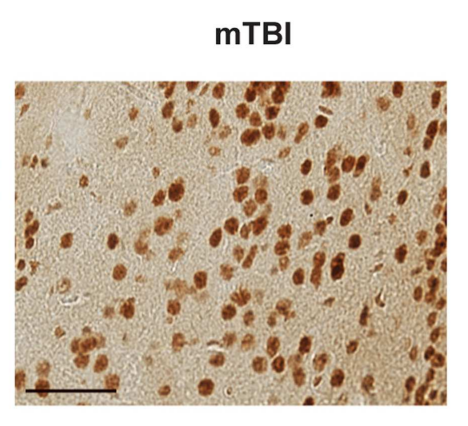

B

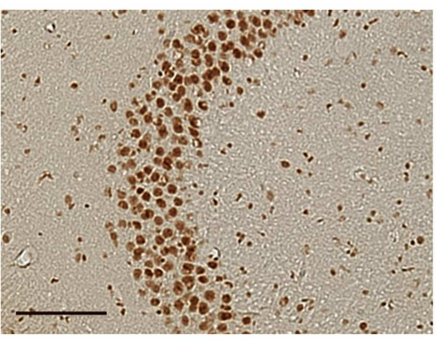

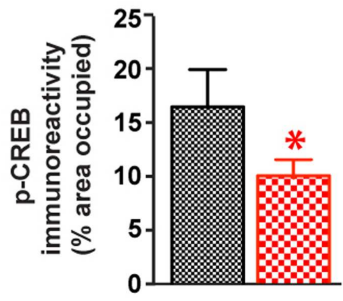

D

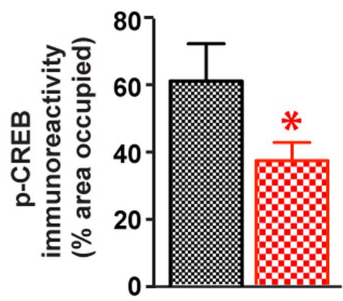

FIGURE 9 | cAMP responsive element binding protein phosphorylation was significant reduced after repetitive $\mathbf{m T B I}$ Wild-type C57BL/6J mice (male, 3 months of age) received three mild impacts (mTBI) or underwent sham procedures (sham). Mice were sacrificed 6 months later and brains were fixed for immunohistochemistry with an antibody against p-CREB. Representative images were taken from amygdala (A) and hippocampus (C), and p-CREB immunoreactivity $(\mathbf{B}, \mathbf{D})$ was quantified as percentage of area occupied. Scale bar in $(\mathbf{A}, \mathbf{C})=20 \mu \mathrm{m} . n=8$ (sham) and 15 (mTBI) mice/group. Mean \pm SEM. ${ }^{*} P<0.05$, by $t$ test. can be used to study the long-term neurological and pathological consequences of different numbers and frequencies of mild head injuries, and the molecular mechanisms of repetitive concussive injury to the brain. Our model may also be suitable for evaluating potential therapeutic interventions for mTBI.

\section{ACKNOWLEDGMENTS}

This work was supported by the Center for Tissue Regeneration, Repair and Restoration, VA Palo Alto Health Care System, and a grant from the Department of Veterans Affairs (RX001218, to Tony Wyss-Coray).

\section{REFERENCES}

1. Gerberding JL, Binder S. Report to Congress on Mild Traumatic Brain Injury in the United States: Steps to Prevent a Serious Public Health Problem (2003). Available from: http://www.cdc.gov/ncipc/pub-res/mtbi/mtbireport.pdf

2. Owens BD, Kragh JF Jr, Wenke JC, Macaitis J, Wade CE, Holcomb JB. Combat wounds in operation Iraqi freedom and operation enduring freedom. J Trauma (2008) 64(2):295-9. doi:10.1097/TA.0b013e318163b875

3. Rigg JL, Mooney SR. Concussions and the military: issues specific to service members. PM R (2011) 3(10 Suppl 2):S380-6. doi:10.1016/j.pmrj.2011.08.005

4. Silver JM, McAllister TW, Arciniegas DB. Depression and cognitive complaints following mild traumatic brain injury. Am J Psychiatry (2009) 166(6):653-61. doi:10.1176/appi.ajp.2009.08111676

5. Williams WH, Potter S, Ryland H. Mild traumatic brain injury and postconcussion syndrome: a neuropsychological perspective. J Neurol Neurosurg Psychiatry (2010) 81(10):1116-22. doi:10.1136/jnnp.2008.171298

6. Kibby MY, Long CJ. Minor head injury: attempts at clarifying the confusion. Brain Inj (1996) 10(3):159-86. doi:10.1080/026990596124494

7. Guskiewicz KM, McCrea M, Marshall SW, Cantu RC, Randolph C, Barr W, et al. Cumulative effects associated with recurrent concussion in collegiate football players: the NCAA Concussion Study. JAMA (2003) 290(19):2549-55. doi:10.1001/jama.290.19.2549
8. DeKosky ST, Ikonomovic MD, Gandy S. Traumatic brain injury - football, warfare, and long-term effects. N Engl J Med (2010) 363(14):1293-6. doi:10.1056/NEJMp1007051

9. Vasterling JJ, Verfaellie M, Sullivan KD. Mild traumatic brain injury and posttraumatic stress disorder in returning veterans: perspectives from cognitive neuroscience. Clin Psychol Rev (2009) 29(8):674-84. doi:10.1016/j.cpr.2009. 08.004

10. Galarneau MR, Woodruff SI, Dye JL, Mohrle CR, Wade AL. Traumatic brain injury during operation Iraqi freedom: findings from the United States NavyMarine Corps Combat Trauma Registry. J Neurosurg (2008) 108(5):950-7. doi:10.3171/JNS/2008/108/5/0950

11. Guskiewicz KM, Marshall SW, Bailes J, McCrea M, Cantu RC, Randolph C, et al. Association between recurrent concussion and late-life cognitive impairment in retired professional football players. Neurosurgery (2005) 57(4):719-26. doi:10.1227/01.NEU.0000175725.75780.DD

12. Rabadi MH, Jordan BD. The cumulative effect of repetitive concussion in sports. Clin J Sport Med (2001) 11(3):194-8. doi:10.1097/00042752-200107000-00011

13. Barkhoudarian G, Hovda DA, Giza CC. The molecular pathophysiology of concussive brain injury. Clin Sports Med (2011) 30(1):33-48. doi:10.1016/j.csm. 2010.09.001

14. Stern RA, Riley DO, Daneshvar DH, Nowinski CJ, Cantu RC, McKee AC. Longterm consequences of repetitive brain trauma: chronic traumatic encephalopathy. PM R (2011) 3(10 Suppl 2):S460-7. doi:10.1016/j.pmrj.2011.08.008

15. Omalu BI, DeKosky ST, Minster RL, Kamboh MI, Hamilton RL, Wecht CH. Chronic traumatic encephalopathy in a National Football League player. Neurosurgery (2005) 57(1):128-34. doi:10.1227/01.NEU.0000163407.92769.ED

16. McKee AC, Cantu RC, Nowinski CJ, Hedley-Whyte ET, Gavett BE, Budson $\mathrm{AE}$, et al. Chronic traumatic encephalopathy in athletes: progressive tauopathy after repetitive head injury. J Neuropathol Exp Neurol (2009) 68(7):709-35. doi:10.1097/NEN.0b013e3181a9d503

17. Xiong Y, Mahmood A, Chopp M. Animal models of traumatic brain injury. Nat Rev Neurosci (2013) 14(2):128-42. doi:10.1038/nrn3407

18. Marklund N, Hillered L. Animal modelling of traumatic brain injury in preclinical drug development: where do we go from here? Br J Pharmacol (2011) 164(4):1207-29. doi:10.1111/j.1476-5381.2010.01163.x 
19. Gold EM, Su D, Lopez-Velazquez L, Haus DL, Perez H, Lacuesta GA, et al. Functional assessment of long-term deficits in rodent models of traumatic brain injury. Regen Med (2013) 8(4):483-516. doi:10.2217/rme.13.41

20. Dewitt DS, Perez-Polo R, Hulsebosch CE, Dash PK, Robertson CS. Challenges in the development of rodent models of mild traumatic brain injury. J Neurotrauma (2013) 30(9):688-701. doi:10.1089/neu.2012.2349

21. Weber JT. Experimental models of repetitive brain injuries. Prog Brain Res (2007) 161:253-61. doi:10.1016/S0079-6123(06)61018-2

22. Luo J, Ho PP, Buckwalter MS, Hsu T, Lee LY, Zhang H, et al. Glia-dependent TGF-beta signaling, acting independently of the TH17 pathway, is critical for initiation of murine autoimmune encephalomyelitis. J Clin Invest (2007) 117(11):3306-15. doi:10.1172/JCI31763

23. Zhu L, Ramboz S, Hewitt D, Boring L, Grass DS, Purchio AF. Non-invasive imaging of GFAP expression after neuronal damage in mice. Neurosci Lett (2004) 367(2):210-2. doi:10.1016/j.neulet.2004.06.020

24. Brody DL, Mac Donald C, Kessens CC, Yuede C, Parsadanian M, Spinner $\mathrm{M}$, et al. Electromagnetic controlled cortical impact device for precise, graded experimental traumatic brain injury. J Neurotrauma (2007) 24(4):657-73. doi:10.1089/neu.2006.0011

25. Shitaka Y, Tran HT, Bennett RE, Sanchez L, Levy MA, Dikranian K, et al. Repetitive closed-skull traumatic brain injury in mice causes persistent multifocal axonal injury and microglial reactivity. J Neuropathol Exp Neurol (2011) 70(7):551-67. doi:10.1097/NEN.0b013e31821f891f

26. Paxinos G, Franklin KBJ. The Mouse Brain in Stereotaxic Coordinates. 2nd ed. San Diego: Academic Press (2001).

27. Lin AH, Luo J, Mondshein LH, ten Dijke P, Vivien D, Contag CH, et al. Global analysis of Smad2/3-dependent TGF-beta signaling in living mice reveals prominent tissue-specific responses to injury. J Immunol (2005) 175(1):547-54.

28. Luo J, Lin AH, Masliah E, Wyss-Coray T. Bioluminescence imaging of Smad signaling in living mice shows correlation with excitotoxic neurodegeneration. Proc Natl Acad Sci U S A (2006) 103(48):18326-31. doi:10.1073/pnas.0605077103

29. Khroyan TV, Zhang J, Yang L, Zou B, Xie J, Pascual C, et al. Rodent motor and neuropsychological behavior measured in home cages using the integrated modular platform - SmartCage(TM). Clin Exp Pharmacol Physiol (2012) 39(7):61422. doi:10.1111/j.1440-1681.2012.05719.x

30. Mandillo S, Tucci V, Holter SM, Meziane H, Banchaabouchi MA, Kallnik M, et al. Reliability, robustness, and reproducibility in mouse behavioral phenotyping: a cross-laboratory study. Physiol Genomics (2008) 34(3):243-55. doi:10.1152/physiolgenomics.90207.2008

31. Coutellier L, Usdin TB. Enhanced long-term fear memory and increased anxiety and depression-like behavior after exposure to an aversive event in mice lacking TIP39 signaling. Behav Brain Res (2011) 222(1):265-9. doi:10.1016/j.bbr.2011. 02.043

32. Villeda SA, Luo J, Mosher KI, Zou B, Britschgi M, Bieri G, et al. The ageing systemic milieu negatively regulates neurogenesis and cognitive function. Nature (2011) 477(7362):90-4. doi:10.1038/nature10357 Epub 2011/09/03.,

33. Faizi M, Bader PL, Saw N, Nguyen TV, Beraki S, Wyss-Coray T, et al. Thy1hAPP(Lond/Swe+) mouse model of Alzheimer's disease displays broad behavioral deficits in sensorimotor, cognitive and social function. Brain Behav (2012) 2(2):142-54. doi:10.1002/brb3.41

34. Hughes RN. The value of spontaneous alternation behavior (SAB) as a test of retention in pharmacological investigations of memory. Neurosci Biobehav Rev (2004) 28(5):497-505. doi:10.1016/j.neubiorev.2004.06.006

35. Luo J, Ho P, Steinman L, Wyss-Coray T. Bioluminescence in vivo imaging of autoimmune encephalomyelitis predicts disease. J Neuroinflammation (2008) 5:6. doi:10.1186/1742-2094-5-6

36. Britschgi M, Takeda-Uchimura Y, Rockenstein E, Johns H, Masliah E, Wyss-Coray T. Deficiency of terminal complement pathway inhibitor promotes neuronal tau pathology and degeneration in mice. J Neuroinflammation (2012) 9:220. doi:10.1186/1742-2094-9-220

37. Luo J, Elwood F, Britschgi M, Villeda S, Zhang H, Ding Z, et al. Colonystimulating factor 1 receptor (CSF1R) signaling in injured neurons facilitates protection and survival. J Exp Med (2013) 210(1):157-72. doi:10.1084/jem. 20120412

38. Kandel ER. The molecular biology of memory storage: a dialogue between genes and synapses. Science (2001) 294(5544):1030-8. doi:10.1126/science.1067020

39. Lonze BE, Ginty DD. Function and regulation of CREB family transcription factors in the nervous system. Neuron (2002) 35(4):605-23. doi:10.1016/S08966273(02)00828-0

40. Atkins CM, Falo MC, Alonso OF, Bramlett HM, Dietrich WD. Deficits in ERK and CREB activation in the hippocampus after traumatic brain injury. Neurosci Lett (2009) 459(2):52-6. doi:10.1016/j.neulet.2009.04.064

41. Hu B, Liu C, Bramlett H, Sick TJ, Alonso OF, Chen S, et al. Changes in trkB-ERK1/2-CREB/Elk-1 pathways in hippocampal mossy fiber organization after traumatic brain injury. J Cereb Blood Flow Metab (2004) 24(8):934-43. doi:10.1097/01.WCB.0000125888.56462.A1

42. Konrad K, Gauggel S, Manz A, Scholl M. Inhibitory control in children with traumatic brain injury (TBI) and children with attention deficit/hyperactivity disorder (ADHD). Brain Inj (2000) 14(10):859-75. doi:10.1080/026990500445691

43. Kane MJ, Angoa-Perez M, Briggs DI, Viano DC, Kreipke CW, Kuhn DM. A mouse model of human repetitive mild traumatic brain injury. J Neurosci Methods (2012) 203(1):41-9. doi:10.1016/j.jneumeth.2011.09.003

44. Povlishock JT. Pathobiology of traumatically induced axonal injury in animals and man. Ann Emerg Med (1993) 22(6):980-6. doi:10.1016/S0196-0644(05) 82738-6

45. Baugh CM, Stamm JM, Riley DO, Gavett BE, Shenton ME, Lin A, et al. Chronic traumatic encephalopathy: neurodegeneration following repetitive concussive and subconcussive brain trauma. Brain Imaging Behav (2012) 6(2):244-54 doi:10.1007/s11682-012-9164-5

46. Papa L, Lewis LM, Falk JL, Zhang Z, Silvestri S, Giordano P, et al. Elevated levels of serum glial fibrillary acidic protein breakdown products in mild and moderate traumatic brain injury are associated with intracranial lesions and neurosurgical intervention. Ann Emerg Med (2012) 59(6):471-83. doi:10.1016/j.annemergmed.2011.08.021

47. Zohar O, Rubovitch V, Milman A, Schreiber S, Pick CG. Behavioral consequences of minimal traumatic brain injury in mice. Acta Neurobiol Exp (2011) 71(1):36-45.

Conflict of Interest Statement: The authors declare that the research was conducted in the absence of any commercial or financial relationships that could be construed as a potential conflict of interest.

Received: 21 July 2013; accepted: 17 January 2014; published online: 04 February 2014. Citation: Luo J, Nguyen A, Villeda S, Zhang H, Ding Z, Lindsey D, Bieri G, Castellano JM, Beaupre GS and Wyss-Coray T (2014) Long-term cognitive impairments and pathological alterations in a mouse model of repetitive mild traumatic brain injury. Front. Neurol. 5:12. doi: 10.3389/fneur.2014.00012

This article was submitted to Neurotrauma, a section of the journal Frontiers in Neurology.

Copyright (c) 2014 Luo, Nguyen, Villeda, Zhang, Ding, Lindsey, Bieri, Castellano, Beaupre and Wyss-Coray. This is an open-access article distributed under the terms of the Creative Commons Attribution License (CC BY). The use, distribution or reproduction in other forums is permitted, provided the original author(s) or licensor are credited and that the original publication in this journal is cited, in accordance with accepted academic practice. No use, distribution or reproduction is permitted which does not comply with these terms. 